\title{
SPECTRAL STRATIGRAPHY AND CLAY MINERALS ANALYSIS IN PARTS OF HELLAS PLANITIA, MARS
}

\author{
${ }^{*}$ I. C. Das ${ }^{1}$, Jyoti Joseph ${ }^{1}$, S.K. Subramanian ${ }^{1}$ and V.K. Dadhwal ${ }^{1}$ \\ ${ }^{1}$ National Remote Sensing Centre, ISRO, Hyderabad - (das_ic, manian_sks, vkdadhwal)@nrsc.gov.in; jyotijesna@gmail.com
}

\begin{abstract}
KEY WORDS: Spectral analysis, Hellas Planitia, Clay minerals, MRO-CRISM, Compositional stratigraphy
\end{abstract}
\begin{abstract}
:
Absorption features that occur in reflectance spectra are a sensitive indicator of mineralogy and chemical composition for a wide variety of materials. The investigation of the mineralogy and chemical composition of surfaces give information about the origin and evolution of planetary bodies. On Mars, the processes of formation of different types of clay minerals result from different types of wet conditions viz. hydrothermalism, subsurface/groundwater weathering, surface alteration etc. The image analyzed in the present study was frt000947f164-trr3 (-27.87N-65.06E). Through the spectral stratigraphic characterization along a crater wall, eight (8) different layers were identified considering the spectral variability and their position. In Hellas Planitia, the alteration minerals identified by CRISM based on distinctive absorptions from 0.4 to $3.9 \mu \mathrm{m}$ include Al-rich smectite, montmorillonite, phyllosilicate mineral at $2.2 \mu \mathrm{m}$ and $2.35 \mu \mathrm{m}$, including strong absorption feature noticed at $1.9 \mu \mathrm{m}$. We conclude that the layers exposed in the crater wall help characterize the compositional stratigraphy for confirming the presence of hydrated minerals in this region as an outcome of geohydrological weathering process.
\end{abstract}

\section{INTRODUCTION}

The hydrological cycle has played a major part or at least a part in the vast process of erosion which marks the most ancient terrain on Mars (Morris et al., 2000). Modeling of Mars' Noachian and early Hesperian hydrologic cycle by AndrewsHanna et al. (2007, 2008) provides an explanation for the source of the groundwater. In their model, precipitation is assumed to have occurred uniformly at latitudes towards equator $\left( \pm 45^{\circ}\right)$ and to have infiltrated a permeable surface, leaching subsurface rocks and accumulating salinity. The study of minerals like hydrous sulfates, phyllosilicates, carbonates and hydrous silica (opal) can highlight the Martian environmental conditions. On Mars the processes of formation of different types of clay minerals result from different types of wet conditions viz. hydrothermalism,

subsurface/groundwater weathering, surface alteration etc (Hughes, 2012). Hydrous silica (opal) is the other mineral which is product of precipitated material formed generally from the chemical weathering of basaltic lava flows, volcanic ash and impact glasses. Oxides such as limonite and hematite are the important hydrous minerals which can contribute the information related to alteration processes. The study of these minerals offer proof of the presence of water at times in the Martian past and can help in the study of Red Planet's environmental history

In this study Mars Reconnaissance Orbiter (MRO) Compact Reconnaissance Imaging Spectrometer for Mars (CRISM) data was used to refine the mineralogy and stratigraphy of the parts of Hellas Planitia in the southern hemisphere of Mars. The CRISM was selected in this study due to its spectral range of 0.4-3.9 $\mu \mathrm{m}$, which covers electronic transition absorptions due to olivine and pyroxene and their ferric alteration products, and vibrational absorptions due to $\mathrm{H}_{2} \mathrm{O}, \mathrm{OH}, \mathrm{CO}_{3}$, and $\mathrm{SO}_{4}$ in alteration products including phyllosilicates, hydrated silica, sulfates, hydroxides, and carbonates (Murchie et al., 2009). The objective was to prepare the spectral stratigraphy across the crater wall to understand the geo-hydrological weathering process and compositional stratigraphy in a region of probable hydrological regime. In addition Spectral characterization was to be carried out for each identified layer for understanding the presence of hydrated minerals.

\section{STUDY AREA}

Most of the layered outcrops on Mars are exposed in abelt between $30^{\circ} \mathrm{N}$ and $30^{\circ} \mathrm{S}$ and their distribution is clustered in the Valles Marineris, Mawrth Vallis, western Arabia Terra, Terra Meridiani and northern Hellas regions (Malin and Edgett, 2000). Hellas is the largest well-preserved impact structure on Mars and spans more than 2000 kilometers across in the southern hemisphere, a region that is much more heavily cratered and higher in average elevation than the northern hemisphere. This region is often referred to as the "southern cratered highlands". Hellas Planitia is thought to have been formed during the Late Heavy Bombardment period of the solar system, which is believed to have taken place in the early Noachian epoch from 3.9 to 4.6 billion years ago when an asteroid hit the Martian surface. In its time of formation, Hellas region has been subject to infilling by eolian, fluvial, glacial, and volcanic materials (Wilson et al. 2007).

\section{DATA USED}

MRO CRISM TRDR (Targeted Reduced Data Record) data which is radiometrically calibrated experiment data records were downloaded from the PDS (Planetary Data System, NASA) for the year 2007 and 2008 to carry out the present analysis. CRISM has the characteristic spectral resolution of $6.55 \mathrm{~nm}$ obtained in the electromagnetic spectrum of the range between 0.362 to 3.920 microns. Spatial resolution varies between $15.7-19.7 \mathrm{~m}$ for VNIR bands and $35 \mathrm{~m}$ for SWIR bands with swath 9.4-11.9 km (Pelkey et al. 2007, Murchie et al. 2007). These data were processed and analyzed using 
$\mathrm{IDL} / \mathrm{ENVI}^{\odot}$ and the CRISM Analysis Toolkit (CAT) (Murchie et al.2007).

\subsection{Preprocessing of TRDR data}

Number of corrections was applied to the downloaded data to make it compatible for analysis. First the photometric correction $[\mathrm{COS}$ (i)] was applied to correct the first order radiance for non-normal solar incidence. Next, Volcano Scan atmospheric correction was applied to correct spectrum for absorption by $\mathrm{CO}_{2}$ (IR only). Then CIRRUS (CRISM Clean), Destripe (VNIR, IR), Despike (IR) was applied to remove isolated noise spikes and correcting column bias. Next, the data was projected using coordinates to make it a referenced image cube.

\subsection{Data processing}

Planetary science applications present the case of complex mineral behavior including impure mineral constituents even at sub-pixel level, dust and debris lying above the substrate and contributions from unknown minerals. Techniques to reduce noise, correct systematic errors, and enhance faint spectral features thus become vital to useful interpretation.

One common strategy for enhancing interesting mineral features in reflectance spectra is the division of a feature target by a neutral spectrum. This neutral spectrum is generated by averaging over a Neutral Region (NR) drawn from the same image (Pelkey et al., 2007). The NR is not precisely defined: should be spectrally "bland" i.e., lacking the spectral features of interest. Instead, it is comprised of the background continuum and any noise artifacts or atmospheric absorption features that are common across the entire image (Murchie et al. 2007, Morgan et al. 2009). The neutral spectrum then serves as a divisor to a target spectrum.

$$
S_{\text {ratioed }}=S_{\text {original }} / S_{\text {neutral }}
$$

\subsection{Flat pixel correction}

NR are often used in planetary geology as spectral divisors to region of interest (ROI), both to enhance key mineralogical signatures and correct for systematic errors such as residual atmospheric distortion. Often geologists prefer regions that are visually dark (absorptive, not shadowed and have fairly uniform texture). Dusty, Sandy or granular regions are often chosen due to the nonlinear convolutions of multiple scattering sources. If these small scattering bodies are dark (absorptive) it can be shown that distinctive mineral features are generally suppressed relative to the continuum background making them ideal for NR selection (Thompson et al., 2010).

After many manual trial and error research across many pixels and region of interest (ROI), the most appropriate flat pixel selected was centered around $\mathrm{X}: 437 \mathrm{Y}: 363$ for the image frt000947f-164-trr3 (-27.87N-65.06E). By using this flat pixel, the ratio spectra were generated for different material by taking the ratio of original pixel $\left(S_{\text {original }}\right)$ and flat $\operatorname{pixel}\left(S_{\text {neutral }}\right)$.
Several image processing techniques such as ratio transformation, multi band statistics were applied to IR image of CRISM data for enhancing the spectral response of the materials present in the image. We used band $6(1.03 \mu \mathrm{m})-$ red filter, band $184(2.2 \mu \mathrm{m})$-green filter and also band 206 $(2.35 \mu \mathrm{m})$-red filter for making a hybrid FCC to highlight the presence of iron oxide minerals and hydrated minerals (Fig. 1). From the image we can infer that the $\mathrm{Fe} / \mathrm{Mg}$ rich phyllosilicates (cyan color) are present across the crater wall and in the colluvial material deposited at the corner of the crater floor (Das, 2004).

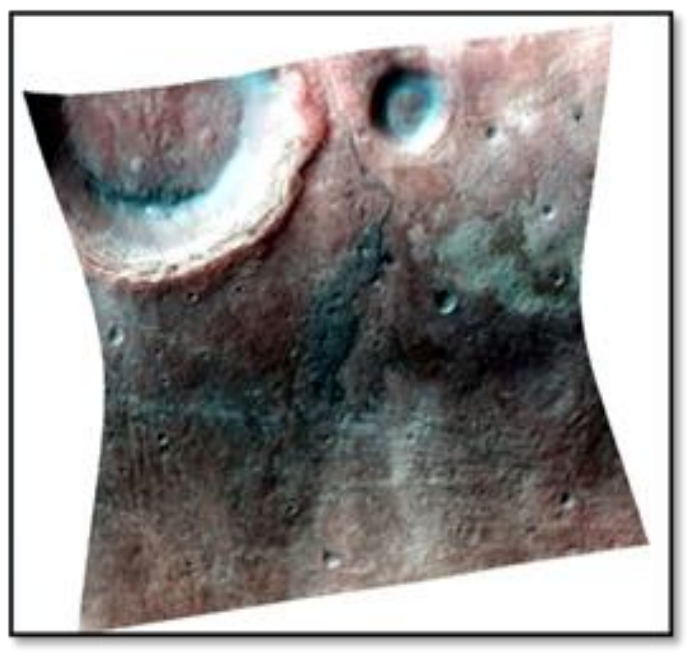

Figure 1: Hybrid FCC generated using geologically significant bands $1.03 \mu \mathrm{m}$ (red), $2.2 \mu \mathrm{m}$ (green) and $2.35 \mu \mathrm{m}$ (blue) representing Iron $(\mathrm{Fe}), \mathrm{Al}-\mathrm{OH}$ and $\mathrm{Mg}-\mathrm{OH}$ absorption features respectively.

\subsection{Compositional stratigraphy}

The spatial and spectral resolution of MRO instrument is well suited for studying compositional stratigraphy on MARS.CRISM images were used to identify the distinct layers and to reveal the stratigraphic relationships among units. Spectral summary parameters and band depth maps for absorption at 1.9, 2.2, 2.35 $\mu \mathrm{m}$ are used to characterize different layers of rock. Spectral absorption feature at $1.9 \mu \mathrm{m}$ band results from $\mathrm{H}_{2} \mathrm{O}$ in hydrated minerals whereas combination tones of cation-OH result in absorption at $2.2 \mu \mathrm{m}$ for aluminum rich phyllosilicates and between 2.28 and $2.35 \mu \mathrm{m}$ for $\mathrm{Fe} / \mathrm{Mg}$ rich phyllosilicates (Vander Meer, 1995).

A cross section (shown in fig: 2) along a line of section from $X$ to $\mathrm{Y}$ was taken on the image for 8 selected bands for spectral analysis. They include $0.7,1.0,1.1,1.19,1.6,1.9,2.2$ and 2.35 $\mu \mathrm{m}$ bands. The variation of spectral reflectance along the spatial profile $\mathrm{XY}$ were stacked with one another as shown in figure 3. After stacking the spectra, the boundary of the layers was defined by observing the reflectance pattern along the XY profile and stratigraphic layers were separated from each other based on the spectral reflectance curves.

\section{RESULTS AND DISCUSSION}




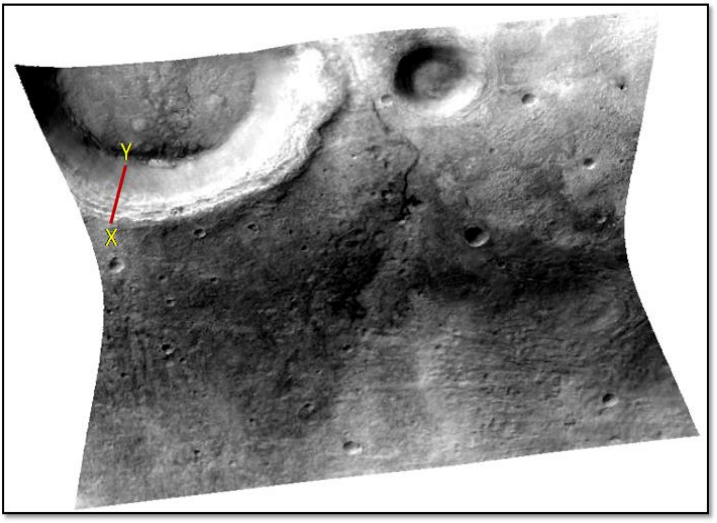

Figure 2: Cross section XY taken along the crater wall for spectral stratigraphy.

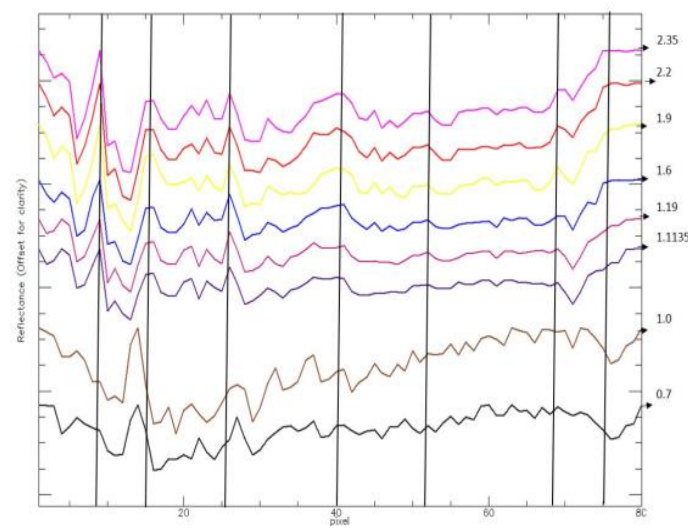

Figure 3: Representing the reflectance spectra of pixels in 8 different layers along spatial profile XY

The spatial profile $\mathrm{XY}$ along the crater wall included 80 pixels in which spectral changes were marked at 7 different locations at pixel number 9, 15, 26, 40, 51, 68 and 75 (Figure 3).

\subsection{Characterization of layers}

Spectra of layer A showed a prominent absorption at $1.9 \mu \mathrm{m}$ and a moderate absorption at 2.28-2.35 $\mu \mathrm{m}$ (figure 4). The absorption at 1.9 indicates the presence of free $\mathrm{H}_{2} 0$ molecules. The slight absorption at $2.28-2.35 \mu \mathrm{m}$ indicates the presence of $\mathrm{Fe} / \mathrm{Mg}$ phyllosilicates like smectite. Layer B spectra showed deep absorption at $1.9 \mu \mathrm{m}$ indicating the presence of free water molecule in hydrated minerals and strong absorption at $2.2 \mu \mathrm{m}$ indicating the presence of $\mathrm{Al}$ rich phyllosilicates like montmorillonite (figure 4). Spectra of layer $\mathrm{C}$ is consistent with a more Al-rich smectite, montmorillonite and a small presence of $\mathrm{Fe} / \mathrm{Mg}$ - rich smectite with negligible inter layer water. Layer D spectra showed only a broad absorption at 1.9 and $2.2 \mu \mathrm{m}$ indicating small presence of $\mathrm{Fe} / \mathrm{Mg}$ rich smectite. Spectra of layer E showed deep absorption at 2.28-2.35 $\mu \mathrm{m}$ indicating the presence of $\mathrm{Fe} / \mathrm{Mg}$ rich phyllosilicates. Layer $\mathrm{F}$ spectra showed deep absorption at $2.2 \mu \mathrm{m}$ indicating Al-rich smectite. Spectra of layer $\mathrm{G}$ and layer $\mathrm{H}$ represent no deep absorptions and spectra's are relatively smooth. This may be because of the signal attenuation of the varying solar incidence angle for these bottom layers (figure 4).

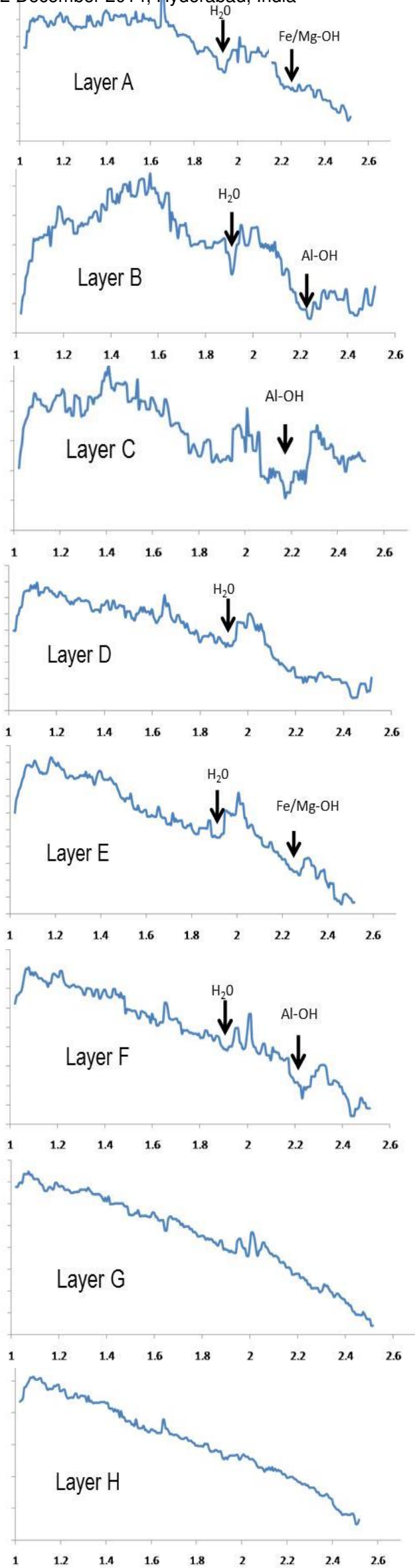

Figure 4. Spectra of each stratigraphic layer showing the characteristic absorption features $(\mathrm{X}$ axis: wavelength and $\mathrm{Y}$ axis: ratio spectra i.e. original pixel/flat pixel) 


\section{CONCLUSIONS}

The altered clay minerals identified by CRISM based on distinctive absorptions from 0.4 to $3.9 \mu \mathrm{m}$ include Al-rich smectite, montmorillonite, and phyllosilicate mineral at $2.2 \mu \mathrm{m}$ and $2.35 \mu \mathrm{m}$ region in this study. The stratigraphic relations among units bearing alteration minerals across the crater wall were layered clays with $\mathrm{Fe} / \mathrm{Mg}$ smectite, Al-rich smectite, montmorillonite and the presence of water in hydrated minerals at $1.9 \mu \mathrm{m}$.

From the presence of hydrated minerals in the Hellas Planitia region, we can conclude that water was present in this area in an earlier Martian regime.

\section{REFERENCES}

Andrews-Hanna, J. C., R. J. Phillips, and M. T. Zuber (2007), Meridiani Planum and the global hydrology of Mars, Nature, 446, 163 - 166,doi:10.1038/nature05594

Andrews-Hanna, J. C., S. M. Wiseman, and R. E. Arvidson (2008), Therole of groundwater in the origin of the indurated layered deposits ofArabia Terra, Mars, Eos Trans. AGU, 89(53), Fall Meet. Suppl., Abstract P44A-01.

Das I.C (2004) Spectral signatures and spectral mixture modeling as a tool for targeting aluminous laterite and bauxite ore deposits, GIS Development net, 2002.

Hughes, A.C.G. (2012). An Evaluation of the History of Aqueous Activity on Mars through a Survey of Select Hypothesized Martian Deltas and Paleo lakes via the Analysis of Mineralogy, Morphology, and Thermophysical Properties. Master's Thesis, University of Tennessee. http://trace.tennessee.edu/utk gradthes/1166.

Malin, M., and Edgett, K., 2000, Evidence for Recent Groundwater Seepage and Surface Runoff on Mars: Science, v. 288, p. 2330-2335.

Morgan, F., Seelos, F., Murchie, S. and the CRISM Team (2009). CRISM Data Users' Workshop CAT Tutorial, March 22, 2009, pages 31 .

Morris, R.V. et.al (2000): Mineralogy, composition and alteration of Mars path finder rock and Soil: Evidence from multispectral, elemental, and magnetic data on terrestrial analogue, SNC meteorite, and Pathfinder samples. Journal of Geophysical Research, Vol. 105, (2000). pp. 1757-1817

Murchie, S., et al. (2007), Compact Reconnaissance Imaging Spectrometer for Mars (CRISM) on Mars Reconnaissance Orbiter (MRO), J. Geophys. Res., 112, E05S03, DOI:10.1029/2006JE002682.

Murchie, S. L., et al. (2009), A synthesis of Martian aqueous mineralogy after 1 Mars year of observations from the Mars Reconnaissance Orbiter, J. Geophys. Res., 114, E00D06, doi:10.1029/2009JE003342.
Pelkey, S. M., et al. (2007), CRISM multispectral summary products: Parameterizing mineral diversity on Mars from reflectance, J. Geophys. Res., 112, E08S14, doi:10.1029/2006JE002831.

Thompson D.R., Mandrake, L. Gilmore, M.S. and Castano, R (2010) Super pixel end member detection, IEEE Geoscience and Remote Sensing, Vol. 48, No. 11, pp. 4023-4033

Van der Meer, F.(1995). Imaging Spectrometry and the Ronda Peridotites (PhD Thesis, Wagenigen Agricultural University, 1995).

Wilson, S.A., Howard, A.D., Moore, J.M. and Grant, J.A. (2007) Geomorphic and stratigraphic analysis of Crater Terby and layered deposits north of Hellas basin, Mars. Journal of Geophysical Research (Planets), 112, E08009, 10.1029/2006JE002830. 